\title{
Decreased ovarian reserve and ovarian morphological alterations in female rat offspring exposed to a ketogenic maternal diet
}

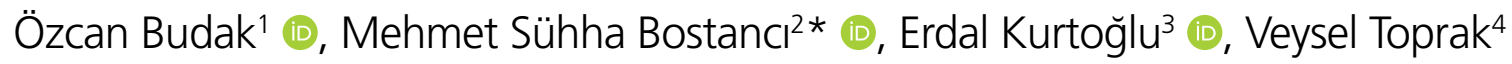

\section{SUMMARY}

OBJECTIVE: This study evaluates the effects of a ketogenic diet on morphology and follicle reserve.

METHOD: Sixteen Sprague-Dawley rats were randomized into two groups: standard diet group $(n=8)$ and ketogenic diet group ( $n=8)$. Rats were time mated. Dams were permitted to deliver spontaneously. The animals were monitored for the onset of puberty. All the rats were weighed and anesthetized, serum anti-Müllerian hormone level was measured, and the oviducts were removed. The morphological characteristics of follicles were determined and total ovarian volumes were calculated.

RESULTS: The mean ovarian volume was statistically significantly lower in the ketogenic diet group compared to the standard diet group $\left(14.41 \pm 0.99 \mathrm{~mm}^{3}\right.$ versus $\left.18.89 \pm 1.28 \mathrm{~mm}^{3}\right)(\mathrm{p}=0.000)$. The mean number of antral follicles was $13.63 \pm 1.80 \mathrm{in}$ the standard diet group and $4.462 \pm 0.760$ in the ketogenic diet group. The mean ovarian weight of the ketogenic diet group was significantly lower than that of the standard diet group $(0.42 \pm 0.06 \mathrm{~g}$ versus $0.815 \pm 107 \mathrm{~g})$. The mean anti-Müllerian hormone levels were significantly higher in the standard diet group compared to the ketogenic diet group $(1.023 \pm 4.75 \mathrm{ng} / \mathrm{mL}$ versus $0.69 \pm 0.07 \mathrm{ng} / \mathrm{mL})(p=0.000)$. The mean percentage of staining of Ki-67 was $35.28 \pm 4.75$ in the standard diet group and $16.98 \pm 3.33$ in the ketogenic diet group $(p=0.000)$.

CONCLUSION: Maternal ketogenic diet reduces ovarian follicular reserve in female offspring and has important implications for maintaining reproductive potential at a population level.

KEYWORDS: Ketogenic diet. Ovarian reserve. Anti-Mullerian hormone. Reproduction.

\section{INTRODUCTION}

Epidemiological and experimental studies show that nutrition and environmental conditions in early life affect development in later life. It has been shown that the mother's nutritional status during pregnancy affects the reproductive potential of the female offspring ${ }^{1}$.

Although an inadequate or inappropriate pregnancy diet causes permanent harmful effects on maternal and fetal metabolism, this results in the changes in fetal physiology ${ }^{2}$. Gestational diets may alter fetal metabolism, and physiology can affect organ development and function ${ }^{3}$.
The maternal gestational diet has been shown to affect numerous parameters of offspring reproductive function, including follicular reserve, ovarian vascularity, and estrus cycle in rat models 4 .

Ketogenic diets $(\mathrm{KD})$ are diets with high-fat, low-carbohydrate content which have effective management of various diseases such as epilepsy and obesity 5 . Physiological ketosis might be beneficial in improving obesity, type 2 diabetes, and cardiovascular disease risk factors ${ }^{6}$. It has been reported that the $\mathrm{KD}$ also has effects on polycystic ovary syndrome, which

\footnotetext{
'Sakarya University, Faculty of Medicine, Department of Histology and Embryology and Artificial Reproductive Techniques - Sakarya, Turkey. ${ }^{2}$ Sakarya University, Faculty of Medicine, Department of Obstetrics and Gynecology and Artificial Reproductive Techniques - Sakarya, Turkey. ${ }^{3}$ Erciyes University, Faculty of Medicine, Department of Anatomy - Kayseri, Turkey.

${ }^{4}$ Private Tatvan Can Hospital, Department of Obstetrics and Gynecology - Bitlis, Turkey.

*Corresponding author: msbostanci@sakarya.edu.tr

Conflicts of interest: the authors declare there are no conflicts of interest. Funding: none.

Received on August 12, 2021. Accepted on August 14, 2021.
} 
is an important endocrine problem in gynecology and the risk of type 2 diabetes increases in the follow-up ${ }^{7}$.

However, it has been shown that a high-fat diet (HFD), which has similar fat content to KD, can adversely affect obesity, follicular growth, and development in mice ${ }^{8}$.

Previous studies of gestational ketosis have focused on maternal ketosis caused by malnutrition, prolonged hunger, or diabetes? However, these conditions and their consequences are different from stable ketosis resulting from the consumption of $\mathrm{KD}$.

We compared the differences in the number of primordial, primary, secondary, and antral follicles; cycle start days; ovarian volume; anti-Müllerian hormone (AMH) levels; and Ki67 of female offspring of rats fed with the $\mathrm{SD}$ and $\mathrm{KD}$ during preconception and pregnancy period. Evaluation of the main components of reproductive system functioning was performed by examining the ovaries and ovarian follicles, in order to reveal the influence in the offspring.

\section{METHODS}

\section{Ethics and animals}

The study was conducted in Sakarya University's SÜDETAM laboratory under the authority of Sakarya University's experimental animal ethics committee on November 4, 2020, under decision no. 62. According to the "The European Commission Directive 86/609/ECC guideline” protocol, applications for all research animals were carried out.

A total of 16 Sprague-Dawley rats (weight 200-250 g; age 65-75 days) were kept under a 12-h light/dark cycle and at a constant temperature of $22 \pm 2^{\circ} \mathrm{C}$ with food and water available ad libitum. Rats were randomized into two groups: standard diet (SD) group ( $\mathrm{n}=8)$ and $\mathrm{KD}$ group $(\mathrm{n}=8)$.

Both diets were manufactured by Arden Research $\&$ Experiment, Ankara, Turkey. SD consists of 5\% fat, 76.1\% carbohydrate, and $18.9 \%$ protein. KD consists of $67.4 \%$ fat, $0.6 \%$ carbohydrate, and $15.3 \%$ protein.

Rats were time mated, then housed individually in standard rat cages with free access to water at a constant temperature maintained at $25^{\circ} \mathrm{C}$ and a 12 -h light/dark cycle. Dams were permitted to deliver spontaneously. On the day of birth, the number of female rats was 35 in the SD group and 26 in the $\mathrm{KD}$ group.

At the beginning on PND 28, the animals were monitored daily for the vaginal opening, a physical marker of the onset of puberty.

All the rats were anesthetized by an intramuscular administration of $50 \mathrm{mg} / \mathrm{kg}$ ketamine hydrochloric acid (Ketalar; Eczacibasi Warner-Lambert, Istanbul, Turkey) and $7 \mathrm{mg} / \mathrm{kg}$ xylazine hydrochloric acid (Rompun; Bayer, Istanbul, Turkey). They were decapitated immediately. The blood samples were collected to measure the serum AMH levels. The aseptic technique was used to make a ventral midline incision expose the reproductive organs, and the oviducts were removed.

Previously fixed ovaries were embedded in paraffin, cut into $5 \mu \mathrm{m}$, and stained with hematoxylin and eosin (HE). Histological assessments were performed by the same pathologist, who was blinded to the study conditions (Figures 1A and 1B).

The morphological characteristics of follicles were determined according to the previous report as follows ${ }^{10,11}$ :

- Primordial follicle, a single oocyte surrounded by a monolayer of squamous cells;

- Primary follicle, an oocyte without antrum surrounded by a monolayer or more than one cuboid or prismatic cell;

- Secondary follicle, consisting of a single oocyte and a single antrum;

- Antral follicle, consisting of a single oocyte and enlarged antrum;

- Corpus luteum, consisting of large volumes of luteal cells surrounded by capillary blood vessels ${ }^{10,11}$.

\section{Histological preparation for volume measurement}

Histological sections were stained with HE and then examined under an inverted microscope (Nikon Eclipse-TI, USA). Ovarian sections were photographed digitally at $4 \times$ magnification using a reference ruler.

\section{Volume calculation}

ImageJ software was used (http://www.rsb.info.nih.gov/ij/download) in order to measure the images obtained from histologically prepared sections. Total ovarian volumes were calculated using the following formula from pictures obtained from the consecutive histological sections: $\mathrm{V}_{\text {ovary }}=\operatorname{tx} \operatorname{Px} \Sigma_{\mathrm{i}=1}^{\mathrm{N}} \mathrm{Ai}^{12}$

\section{Immunohistochemical analysis}

Tissue samples to be made immunohistochemical (IHC) analysis for Ki-67 immunoreactivity evaluation, a light microscope at 200× magnification (Nikon Eclipse Ni invert microscope) was examined (Figures 1C and 1D). A scoring system has used the protocol reported by Panzan et al. ${ }^{13}$ Immunoexpression was evaluated at $400 \times$ magnification using the semiquantitative method.

\section{Hormonal assays}

$\mathrm{AMH}$ was quantitatively estimated in rat serum samples using enzyme-linked immunosorbent assay (ELISA) kits (My 

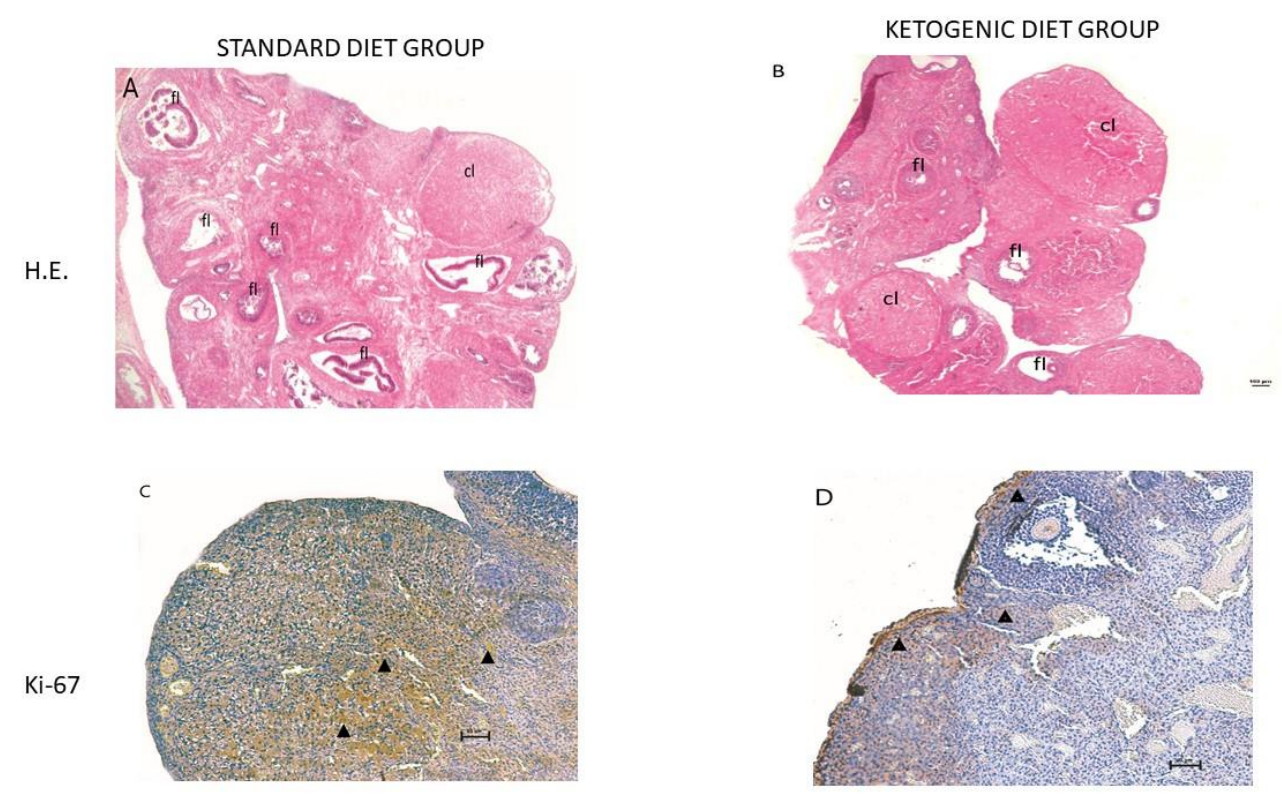

Figure 1. Fl: follicles; $\mathrm{CL}$ : corpora lutea. Standard and ketogenic diet ovarian Hematoxylin and eosin stain (HE) and Ki-67 immunohistochemistry pictures, 40×100 scale bar. The number of follicles was higher in the Standard diet group (A) compared to the ketogenic diet group (B). Ki-67 immunohistochemistry positivity was observed to be more intense in the Standard diet group (C) compared to the ketogenic group (D); brown-stained cells are considered positive (black arrowhead).

BioSource, Rat AMH ELISA Kit catalog no: MBS2509909, San Diego, CA, USA).

\section{Statistical analysis}

Statistical analyses were performed using the SPSS 24.0 package program (SPSS Inc. and Lead Tech. Inc., Chicago, IL, USA). The variables were investigated using visual and the analytical methods Kolmogorov-Smirnov test to determine whether they are normally distributed. Mann-Whitney U test was used for the non-normally distributed numerical data. While investigating the associations between non-normally distributed variables, the correlation coefficients and their significance were calculated using the Spearman test. Results are given as mean \pm standard deviation. For all statistical analyses, a two-tailed $\mathrm{p}<0.05$ was considered statistically significant.

\section{RESULTS}

In our study, we obtained 35 female offspring in the SD group and 26 in the KD group. We found the mean ovarian volume of $18.89 \pm 1.28 \mathrm{~mm}^{3}$ in the SD group and $14.41 \pm 0.99 \mathrm{~mm}^{3}$ in the $\mathrm{KD}$ group $(\mathrm{p}=0.000)$ (Figure $2 \mathrm{~A})$.

The mean number of primordial follicles was $106.94 \pm 4.57$ in the $\mathrm{SD}$ group and $59.54 \pm 4.13$ in the $\mathrm{KD}$ group $(\mathrm{p}=0.000)$ (Figure 2B).
The number of primary follicles was $62 \pm 4.04$ in the SD group and that in the $\mathrm{KD}$ group was decreased to $31.03 \pm 3.79$ $(\mathrm{p}=0.000)$ (Figure 2C).

The mean number of secondary follicles was $33.34 \pm 3.39$ in the SD group and $11.77 \pm 1.84$ in the $\mathrm{KD}$ group $(\mathrm{p}=0.000)$ (Figure 2D).

The mean number of antral follicles was $13.63 \pm 1.80$ in the SD group and $4.462 \pm 0.760$ in the $\mathrm{KD}$ group $(\mathrm{p}=0.000)$ (Figure 2E). The mean corpus luteum count was $7.54 \pm 0.78$ in the SD group and 2.038 \pm 0.662 in the KD group (Figure $2 \mathrm{~F}$ ).

The mean ovarian weight of the SD group was significantly lower than that of the KD group $(0.815 \pm 107 \mathrm{~g}$ versus $0.42 \pm 0.06 \mathrm{~g})(\mathrm{p}=0.000)$ (Figure $2 \mathrm{G})$.

The mean AMH levels were significantly higher in the SD group compared to the $\mathrm{KD}$ group $(1.023 \pm 4.75 \mathrm{ng} / \mathrm{mL}$ versus $0.69 \pm 0.07 \mathrm{ng} / \mathrm{mL})(\mathrm{p}=0.000)$ (Figure $2 \mathrm{H})$.

The mean percentage of staining of Ki-67 was $35.28 \pm 4.75$ in the $\mathrm{SD}$ group and $16.98 \pm 3.33$ in the $\mathrm{KD}$ group $(\mathrm{p}=0.000)$ (Figure 2I).

The correlation between the ovarian volumes and the number of primordial follicles, AMH levels, and Ki-67 staining percentages shows no statistically significant difference between the SD and KD groups.

The results were as follows: for KD group, the ovarian volumes and the number of primordial follicles $(\mathrm{p}=0.676, \mathrm{r}=0.086$ ), 


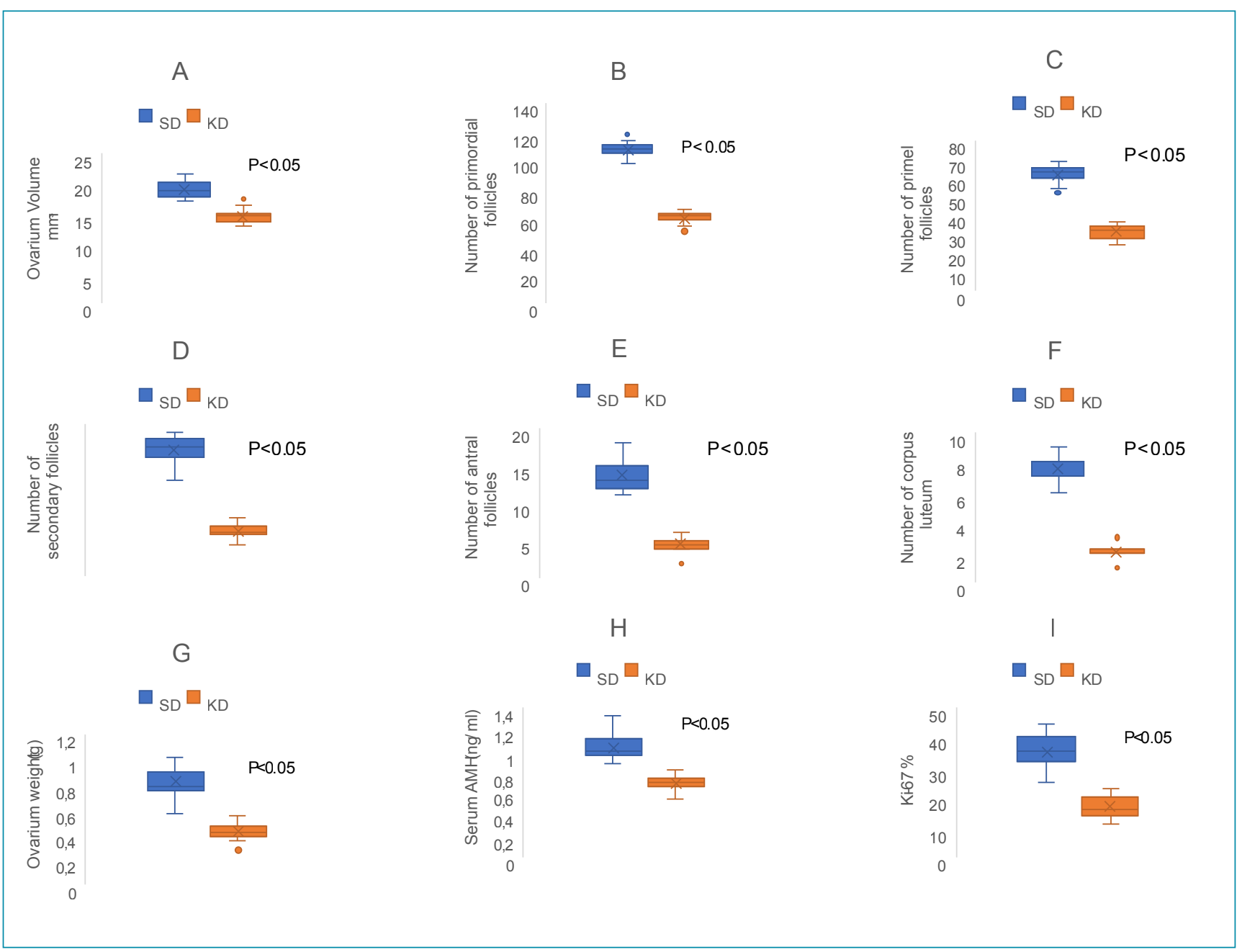

Figure 2. (A) Comparison of ovarian volume; (B) and comparison of number of primordial primary; (C) secondary; (D) antral; (E) number of corpus luteum; (F) ovarian weight; (G) serum AMH concentrations; (H) and Ki-67 staining percentages; (I) in standard diet and ketogenic diet groups. Box plot shows the comparison of standard diet and ketogenic diet (standard diet $n=35$; ketogenic diet $n=26$ ).

Ki-67 concentration ( $\mathrm{p}=0.229, \mathrm{r}=0.244)$, and $\mathrm{AMH}(\mathrm{p}=0.312$, $\mathrm{r}=-0.206)$. For $\mathrm{SD}$ group, the ovarian volumes and the number of primordial follicles $(\mathrm{p}=0.688, \mathrm{r}=-0.070)$, Ki- 67 concentration $(\mathrm{p}=0.344, \mathrm{r}=-0.165)$, and AMH $(\mathrm{p}=0.803, \mathrm{r}=-0.044)$.

\section{DISCUSSION}

This study shows that maternal gestational KD leads to follicular defects occurring during fetal life in oocyte and follicular development offspring. Pregnancy is the critical window of fetal ovarian vulnerability of mothers' offspring and has shown a loss of oocyte-derived follicular growth factors and increased oxidative stress levels ${ }^{14}$. Exposure to a suboptimal environment during fetal and early postnatal development has to impair the programming of offspring ovarian reserve in animal models ${ }^{15}$.
Although we know that the KD exhibits anti-inflammatory properties ${ }^{16}$, our experiments demonstrate the adverse effects of the maternal KD on the follicular count of offspring. These adverse effects in our study were similar to the findings found due to studies using $\mathrm{HFDs}^{17}$. KD, which is similar to HFD in content, affects ovaries similar to HFD.

It is known that maternal obesity due to HFD seriously affects offspring phenotype by altering fetal programming in various systems, including reproduction ${ }^{18}$. Our study observed these results, which developed due to obesity caused by HFD, without resulting in obesity in $\mathrm{KD}$.

Pubertal timing and ovarian function in female rats are affected by maternal calorie restriction and maternal high-fat nutritional status ${ }^{19}$. Studies on HFD have shown the adverse effects of obesity on oocyte count, quality and maturity, fertilization rate, and subsequent embryo quality ${ }^{20}$. Connor et al. ${ }^{21}$ 
found that pups from high-fat-fed dams exhibit early puberty and irregular estrous cycles by having prolonged and persistent estrus. It has been shown that reproductive function parameters related to steroid synthesis, including pubertal age, affected rat offspring that received an $\mathrm{HFD}^{21}$.

Our study found that puberty occurred earlier in the KD group. All these data indicate that poor quality of nutrition can disrupt ovarian function, especially the development and quality of oocytes.

Expression of the Ki-67 antigen, indicating the proliferative potential of cells, is expressed in all active stages of the cell cycle (G1, S, G2, and mitosis) ${ }^{22}$. The expression of Ki-67 was more apparent in SD follicles than in the KD group. Primordial follicle activation requires a signaling system including cytokines and growth hormones that mediate intercellular communication $^{23}$. This suggests that primordial follicle development due to $\mathrm{KD}$ is negatively affected by this pathway.

Minge et al. ${ }^{20}$ found that mice fed an HFD had delayed embryonic development ${ }^{20}$. Similarly, using mice, Aiken et al. ${ }^{4}$ found no difference in ovarian weight between the two groups. Our study observed that the ovarian volume and ovarian weight decreased in the $\mathrm{KD}$ group without obesity. This situation suggests that local side effects occur on the ovarian tissue without systemic effects such as excessive weight gain in the $\mathrm{KD}$ group. The significantly lower serum AMH level in the KD group than the SD group seems to be compatible with histopathological examination. The mean number of primordial, primary, secondary, antral, and the number of corpus luteum in the KD group displayed a statistical significance difference compared with the SD group. It is known that rat studies cannot fully reflect human physiology. In this case, this constitutes the main limitation of our study.

\section{CONCLUSION}

The maternal $\mathrm{KD}$ may reduce ovarian follicular reserve in offspring. The model may be helpful in future studies providing further insight into the pathophysiology of human reproduction in the setting of the use of $\mathrm{KD}$.

\section{AUTHORS' CONTRIBUTIONS}

ÖB: Conceptualization, Formal analysis, Investigation, Methodology, Project administration, Resources, Supervision, Visualization, Writing - original draft, Writing - review \& editing. MSB: Formal analysis, Methodology, Validation, Visualization, Writing - original draft, Writing - review \& editing. EK: Data curation, Formal analysis, Funding acquisition, Resources, Software. VT: Data curation, Funding acquisition, Resources, Software.

\section{REFERENCES}

1. Chan KA, Tsoulis MW, Sloboda DM. Early-life nutritional effects on the female reproductive system. J Endocrinol. 2015;224(2):R45-62. https://doi.org/10.1530/JOE-14-0469

2. King JC. Physiology of pregnancy and nutrient metabolism. Am J Clin Nutr. 2000;71(Suppl 5):1218S-25S. https://doi. org/10.1093/ajcn/71.5.1218s

3. Godfrey KM, Barker DJ. Fetal nutrition and adult disease. Am J Clin Nutr. 2000;71(Suppl 5):1344S-52S. https://doi. org/10.1093/ajcn/71.5.1344s

4. Aiken CE, Tarry-Adkins JL, Penfold NC, Dearden L, Ozanne $\mathrm{SE}$. Decreased ovarian reserve, dysregulation of mitochondrial biogenesis, and increased lipid peroxidation in female mouse offspring exposed to an obesogenic maternal diet. FASEB J. 2016;30(4):1548-56. https://doi.org/10.1096/fj.15-280800

5. Katyal NG, Koehler AN, McGhee B, Foley CM, Crumrine PK. The ketogenic diet in refractory epilepsy: the experience of Children's Hospital of Pittsburgh. Clin Pediatr (Phila). 2000;39(3):153-9. https://doi.org/10.1177/000992280003900303

6. Caprio $M$, Infante $M$, Moriconi E, Armani A, Fabbri A, Mantovani G, et al. Very-low-calorie ketogenic diet (VLCKD) in the management of metabolic diseases: systematic review and consensus statement from the Italian Society of Endocrinology (SIE). J Endocrinol Invest. 2019;42(11):1365-86. https://doi. org/10.1007/s40618-019-01061-2
7. Neves LPP, Marcondes RR, Maffazioli GN, Simões RS, Maciel GAR, Soares Júnior JM. Nutritional and dietary aspects in polycystic ovary syndrome: insights into the biology of nutritional interventions. Gynecol Endocrinol. 2020;36(12):1047-50. https://doi.org/10.1080/09513590.2020.1822797

8. Jungheim ES, Schoeller EL, Marquard KL, Louden ED, Schaffer JE, Moley KH. Diet-induced obesity model: abnormal oocytes and persistent growth abnormalities in the offspring. Endocrinology. 2010;151(8):4039-46. https://doi.org/10.1210/ en.2010-0098

9. Sussman D, van Eede M, Wong MD, Adamson SL, Henkelman $M$. Effects of a ketogenic diet during pregnancy on embryonic growth in the mouse. BMC Pregnancy Childbirth. 2013;13:109. https://doi.org/10.1186/1471-2393-13-109

10. Cruz G, Barra R, González D, Sotomayor-Zárate R, Lara HE. Temporal window in which exposure to estradiol permanently modifies ovarian function causing polycystic ovary morphology in rats. Fertil Steril. 2012;98(5):1283-90. https://doi.org/10.1016/j. fertnstert.2012.07.1060

11. Damous LL, Carvalho AETS, Nakamuta JS, Shiroma ME, Louzada ACS, Soares Júnior JM, et al. Cell-free therapy with the secretome of adipose tissue-derived stem cells in rats' frozenthawed ovarian grafts. Stem Cell Res Ther. 2018;9(1):323. https://doi.org/10.1186/s13287-018-1054-3 
12. Aho M, Vesterinen E, Meyer B, Purola E, Paavonen J. Natural history of vaginal intraepithelial neoplasia. Cancer. 1991;68(1):195-7. https://doi.org/10.1002/1097-0142(19910701)68:1<195::aidcncr2820680135>3.0.c0;2-I

13. Panzan MQ, Mattar R, Maganhin CC, Simões RS, Rossi AG, Motta EL,et al. Evaluation of FAS and caspase-3 in the endometrial tissue of patients with idiopathic infertility and recurrent pregnancy loss. Eur J Obstet Gynecol Reprod Biol. 2013;167(1):47-52. https://doi.org/10.1016/j. ejogrb.2012.10.021

14. Bernal $A B$, Vickers $M H$, Hampton MB, Poynton RA, Sloboda DM. Maternal undernutrition significantly impacts ovarian follicle number and increases ovarian oxidative stress in adult rat offspring. PLoS One. 2010;5(12):e15558. https://doi. org/10.1371/journal.pone.0015558

15. Guzmán C, García-Becerra R, Aguilar-Medina MA, Méndez I, Merchant-Larios H, Zambrano E. Maternal protein restriction during pregnancy and/or lactation negatively affects follicular ovarian development and steroidogenesis in the prepubertal rat offspring. Arch Med Res. 2014;45(4):294-300. https://doi. org/10.1016/j.arcmed.2014.05.005

16. Dupuis N, Curatolo N, Benoist JF, Auvin S. Ketogenic diet exhibits anti-inflammatory properties. Epilepsia. 2015;56(7):e95-8. https://doi.org/10.1111/epi.13038

17. Zhou Z, Lin Q, Xu X, Illahi GS, Dong C, Wu X. Maternal high-fat diet impairs follicular development of offspring through intraovarian kisspeptin/GPR54 system. Reprod Biol Endocrinol. 2019;17(1):13. https://doi.org/10.1186/s12958-019-0457-z
18. Zambrano E, Guzmán C, Rodríguez-González GL, DurandCarbajal M, Nathanielsz PW. Fetal programming of sexual development and reproductive function. Mol Cell Endocrinol. 2014;382(1):538-49. https://doi.org/10.1016/j. mce.2013.09.008

19. Sloboda DM, Howie GJ, Pleasants A, Gluckman PD, Vickers MH. Pre- and postnatal nutritional histories influence reproductive maturation and ovarian function in the rat. PLoS One. 2009;4(8):e6744. https://doi.org/10.1371/journal.pone.0006744

20. Minge CE, Bennett BD, Norman RJ, Robker RL. Peroxisome proliferator-activated receptor-gamma agonist rosiglitazone reverses the adverse effects of diet-induced obesity on oocyte quality. Endocrinology. 2008;149(5):2646-56. https://doi. org/10.1210/en.2007-1570

21. Connor KL, Vickers MH, Beltrand J, Meaney MJ, Sloboda DM. Nature, nurture or nutrition? Impact of maternal nutrition on maternal care, offspring development and reproductive function. J Physiol. 2012;590(9):2167-80. https://doi.org/10.1113/ jphysiol.2011.223305

22. Cattoretti G, Becker MH, Key G, Duchrow M, Schlüter C, Galle $J$, et al. Monoclonal antibodies against recombinant parts of the Ki-67 antigen (MIB 1 and MIB 3) detect proliferating cells in microwave-processed formalin-fixed paraffin sections. J Pathol. 1992;168(4):357-63. https://doi.org/10.1002/ path. 1711680404

23. Skinner MK. Regulation of primordial follicle assembly and development. Hum Reprod Update. 2005;11(5):461-71. https://doi.org/10.1093/humupd/dmi020 